\title{
Genotator: A disease-agnostic tool for genetic annotation of disease
}

\author{
Dennis P Wall ${ }^{1 *}$, Rimma Pivovarov ${ }^{1,2}$, Mark Tong ${ }^{1}$, Jae-Yoon Jung ${ }^{1}$, Vincent A Fusaro ${ }^{1}$, Todd F DeLuca', \\ Peter J Tonellato ${ }^{1}$
}

\begin{abstract}
Background: Disease-specific genetic information has been increasing at rapid rates as a consequence of recent improvements and massive cost reductions in sequencing technologies. Numerous systems designed to capture and organize this mounting sea of genetic data have emerged, but these resources differ dramatically in their disease coverage and genetic depth. With few exceptions, researchers must manually search a variety of sites to assemble a complete set of genetic evidence for a particular disease of interest, a process that is both timeconsuming and error-prone.

Methods: We designed a real-time aggregation tool that provides both comprehensive coverage and reliable gene-to-disease rankings for any disease. Our tool, called Genotator, automatically integrates data from 11 externally accessible clinical genetics resources and uses these data in a straightforward formula to rank genes in order of disease relevance. We tested the accuracy of coverage of Genotator in three separate diseases for which there exist specialty curated databases, Autism Spectrum Disorder, Parkinson's Disease, and Alzheimer Disease. Genotator is freely available at http://genotator.hms.harvard.edu.

Results: Genotator demonstrated that most of the 11 selected databases contain unique information about the genetic composition of disease, with 2514 genes found in only one of the 11 databases. These findings confirm that the integration of these databases provides a more complete picture than would be possible from any one database alone. Genotator successfully identified at least $75 \%$ of the top ranked genes for all three of our use cases, including a 90\% concordance with the top 40 ranked candidates for Alzheimer Disease.

Conclusions: As a meta-query engine, Genotator provides high coverage of both historical genetic research as well as recent advances in the genetic understanding of specific diseases. As such, Genotator provides a real-time aggregation of ranked data that remains current with the pace of research in the disease fields. Genotator's algorithm appropriately transforms query terms to match the input requirements of each targeted databases and accurately resolves named synonyms to ensure full coverage of the genetic results with official nomenclature. Genotator generates an excel-style output that is consistent across disease queries and readily importable to other applications.
\end{abstract}

\section{Background}

The promise of personalized and genetic-based medicine has encouraged researchers to develop new technologies to search for genetic causes of common disease. More and more genome data are becoming available due to these technological advances in genotyping and increasing numbers of genome-wide association studies (GWAS).

\footnotetext{
* Correspondence: dpwall@hms.harvard.edu

${ }^{1}$ Center for Biomedical informatics, Harvard Medical School, Boston, MA 02115

Full list of author information is available at the end of the article
}

Concomitant with this rise in disease genomics is the rise of publicly accessible databases to report clinical relevance of mutations and provide rankings of genes in terms of their roles in disease. Top among these include several large and established resources like Online Mendelian Inheritance in Man (OMIM) [1], The Human Gene Mutation Database (HGMD) [2], and GeneCards [3] that attempt to cover a wide range of human disease using semi-automated approaches, as well as smaller resources devoted to manual reports of genetic association to high profile diseases, including SFARI Gene for Autism [4],
Ciomed Central

C 2010 Wall et al; licensee BioMed Central Ltd. This is an Open Access article distributed under the terms of the Creative Commons Attribution License (http://creativecommons.org/licenses/by/2.0), which permits unrestricted use, distribution, and reproduction in any medium, provided the original work is properly cited. 
PDGene for Parkinson's Disease (PD) [5], and AlzGene for Alzheimer Disease [6]. The former tend to cover large numbers of human diseases, but also tend to differ, sometimes dramatically, in their concepts of disease-gene association. The latter tend to be rich in content and reliability, but also have a tendency to be incomplete in coverage and lag behind the emerging research trends, at least in part because much of their content is added manually. In addition, the number of such manually curated databases remains restricted to priority diseases for which federal or other funding is available. Many databases are also rarely updated, difficult to navigate, provide information without rankings, maintain inconsistent coverage of information and/or lack a description of their methodology. While all of these resources have merit, a researcher interested in the complete set of the genetic knowledge for a disease or set of diseases is left having to search through a variety of databases to manually compile the results. A resource that automates this process by computationally integrating results from a host of resources to provide best-of-breed genetic knowledge would be a tremendous boon to the field.

Motivated by the need for an integrated system for gene-disease knowledge, we built an engine called Genotator that integrates a wide array of trusted databases and provides a rich set of annotations relating genes to disease. We designed Genotator as a fully automated real-time aggregator of all relevant and up-to-date information about each gene linked to a particular disease. Every disease term queried in the Genotator returns with a list of genes and relevant attributes and annotations for each gene. In the present manuscript we describe the Genotator algorithm and demonstrate its functionality using three use cases, Autism Spectrum Disorder (ASD), Parkinson's Disease (PD), and Alzheimer Disease (AD).

\section{Implementation \\ Databases}

We manually examined 33 external databases and identified 11 that had the depth and breadth appropriate for general disease annotation (Table 1). We chose the original 33 based on disease coverage and comprehensiveness and their amenability to automation via screen scraping or other methods. We also chose only those resources that could be queried by disease to return a gene list and associated attributes, such as supporting citations.

\section{Algorithm}

We designed an algorithm to query a given disease term in the 11 databases described in Table 1 . The code was written in Java and Python and designed to form the union of the lists of genes returned from a disease query while recording whether a gene was present in or absent from each database. We also designed the code to run on a research cluster so that multiple requests could be run in batch on 6 available nodes. The length a single job was dependent on the size of the result set and on the response times of the 11 external resources. As a secondary step, the algorithm queried NCBI with the list of gene symbols to provide an enriched set of annotations including official gene symbol, Ensembl ID, gene ID, gene name, chromosome, location, symbol synonyms, and aliases (Table 2). If separate entries in the results were found to be synonyms, the algorithm collapsed the rows into a single entry under the official NCBI name taking the consensus of the results from all databases queried. The final results were formatted in a single tab-delimited text file for display/download on the Genotator website (example of pipeline provided in Figure 1).

In addition, we included a select group of high-value parameters to enrich the quality of the data with regards to clinical and experimental relevance of each gene. Specifically, we included from HuGE Navigator [7] and the Genetic Association Database [8] the manually assigned labels "Yes Association", "No Association", "Unknown Association" (where yes association indicates positive support for a gene's role in the disease phenotype) for each gene-article pair, $\mathrm{p}$-values from genome-wide association studies, and the Gene Prospector score of association [9]. All key parameters were then compiled into an attribute vector for scoring and ranking of genes (described in the section immediately below). Finally, to obtain a list of publications supporting a gene-disease pair, we queried HuGE Navigator first with the disease of interest and then separately with the gene name (in this case the official gene symbol) and reported the intersecting publications in the final results.

\section{Score}

The final step of the Genotator algorithm was the implementation of a scoring system to assign the strength of association per gene to the disease of interest. The Genotator score (GS) compiled information from the 11 databases using the following formula.

$$
\begin{aligned}
& G S= \\
& \begin{array}{l}
G A D_{Y}-G A D_{N}+\phi(G P S) \\
\quad+1 / \gamma(D B)+1 / \kappa(R E F)
\end{array}
\end{aligned}
$$

$G A D_{Y}=$ Total number of "Yes" labeled associations for the gene and disease in the Genetic Association Database

$G A D_{N}=$ Total number of "No" labeled associations for the gene and disease in the Genetic Association Database GPS = Gene Prospector's score of gene-disease association 
Table 1 Databases integrated within Genotator (Statistics Gathered: June 19, 2010)

\begin{tabular}{|c|c|c|c|}
\hline Database & Website & Description & Statistics \\
\hline GeneCards [3] & [17] & $\begin{array}{l}\text { Searchable database of human genes that provides concise genomic, } \\
\text { genetic and functional information }\end{array}$ & $\begin{array}{l}73,017 \text { Entries, } 28,656 \text { of them with symbols } \\
\text { approved by the HUGO gene nomenclature } \\
\text { committee }\end{array}$ \\
\hline $\begin{array}{l}\text { Genetic } \\
\text { Association } \\
\text { Database [8] }\end{array}$ & [18] & $\begin{array}{l}\text { Archive of human genetic association studies of complex diseases and } \\
\text { disorders }\end{array}$ & 2673 genes for 5636 diseases/phenotypes \\
\hline $\begin{array}{l}\text { HuGE Navigator } \\
\text { [7] }\end{array}$ & {$[19]$} & $\begin{array}{l}\text { Knowledge base including information on gene-disease and gene- } \\
\text { gene associations }\end{array}$ & 9429 genes for 2215 diseases \\
\hline $\begin{array}{l}\text { Human Gene } \\
\text { Mutation } \\
\text { Database [2] }\end{array}$ & [20] & $\begin{array}{l}\text { Database established for the study of mutational mechanisms in } \\
\text { human genes }\end{array}$ & 72414 mutations in public release \\
\hline $\begin{array}{l}\text { Online } \\
\text { Mendelian } \\
\text { Inheritance in } \\
\text { Man [1] }\end{array}$ & [21] & NCBI's compendium of human genes and genetic phenotypes & 13, 158 genes for 2799 phenotypes/diseases \\
\hline $\begin{array}{l}\text { Your Favorite } \\
\text { Gene }\end{array}$ & [22] & $\begin{array}{l}\text { Database containing scientific descriptions and overviews of genes } \\
\text { and their corresponding proteins with links to the most used gene } \\
\text { data-banks }\end{array}$ & $\sim 8595$ genes \\
\hline \multirow[t]{2}{*}{ UniProt [23] } & [24] & $\begin{array}{l}\text { Central database of protein sequences with accurate, consistent, rich } \\
\text { sequence and functional annotation }\end{array}$ & $\begin{array}{l}\text { UniProtKB/Swiss-Prot Release 2010_06 of 18- } \\
\text { May-10 of contains } 517100 \text { sequence entries }\end{array}$ \\
\hline & & & $\begin{array}{l}\text { UniProtKB/TrEMBL Release 2010_07 of 15-Jun- } \\
2010 \text { of contains } 11109684 \text { sequence entries }\end{array}$ \\
\hline PharmGKB [25] & [26] & $\begin{array}{l}\text { Database of primary genotype and phenotype data, annotate gene } \\
\text { variants and gene-drug-disease relationships }\end{array}$ & 3,197 diseases, 26,216 genes \\
\hline Entrez Gene & [27] & $\begin{array}{l}\text { Searchable database of genes, from RefSeq genomes, and defined by } \\
\text { sequence and/or located in the NCBI Map Viewer }\end{array}$ & 42644 genes \\
\hline WikiGenes [28] & [29] & $\begin{array}{l}\text { Non-profit, open access database of articles on genes, proteins and } \\
\text { chemical compounds }\end{array}$ & Global community \\
\hline GenAtlas [30] & [31] & $\begin{array}{l}\text { Database containing relevant information with respect to gene } \\
\text { mapping and genetic diseases }\end{array}$ & 22466 genes/4434 phenotypes \\
\hline
\end{tabular}

$D B=$ Number of total databases (out of 11) that the gene appeared in

$R E F=$ Number of total references for the given gene

The constants $\varphi, \gamma$, and $\kappa$ were used to weight the contributions of the GPS, DB, and REF parameters. We elected to set these values at 100, 10, and 5, respectively, as these numbers provided the best overall performance. However, we designed the Genotator software to enable users the ability to alter these parameters should alternative weighting schemes be desired. In addition, Genotator reports the complete set of attributes together with

Table 2 The characteristics included in Genotator from select resources

\begin{tabular}{|c|c|}
\hline Database & Characteristics Incorporated \\
\hline \multirow[t]{4}{*}{ Genetic Association Database } & List of Genes \\
\hline & "Yes" Association (published statement of link between gene and disease phenotype) \\
\hline & "No" Association (published statement of no link between gene and disease) \\
\hline & p-value (from genome wide association studies) \\
\hline \multirow[t]{3}{*}{ HuGE Navigator } & List of Genes (official gene symbols) \\
\hline & Gene Prospector Score [9] \\
\hline & List of PubMed References \\
\hline \multirow[t]{7}{*}{ Entrez Gene } & List of Genes (official gene symbols) \\
\hline & Official Full Name \\
\hline & Symbol Synonyms \\
\hline & Chromosome Number \\
\hline & Location on Chromosome \\
\hline & Gene ID \\
\hline & Ensembl ID \\
\hline
\end{tabular}

All other databases listed in Table 1 provided a list of genes only. 


\begin{tabular}{|c|c|c|c|c|c|c|c|c|c|c|c|}
\hline \multicolumn{2}{|c|}{$\begin{array}{c}\text { Enter Disease } \\
\text { Term }\end{array}$} & & \multirow{2}{*}{$\begin{array}{l}\text { Query Multiple } \\
\text { Databases }\end{array}$} & \multirow{2}{*}{\multicolumn{2}{|c|}{$\begin{array}{ll}\text { Unorder } \\
\text { Gene Li } \\
\text { NRXN1 } \\
\text { PTEN } \\
\text { SLC6A4 } \\
\text { FMR1 } \\
\text { CDH10 } \\
\text { F } \quad \text { FRAXE } \\
\text { MAOA } \\
\text { FRAXF } \\
\text { MET } \\
\text { TAS2R1 }\end{array}$}} & \multirow{2}{*}{$\begin{array}{l}\text { ed } \\
\text { st }\end{array}$} & \multicolumn{5}{|c|}{$\begin{array}{c}\text { Standardize \& } \\
\text { Annotate }\end{array}$} \\
\hline Disease: & autism & & & & & & \multicolumn{5}{|c|}{$\begin{array}{l}\text { NCBI } \llbracket \text { GAD }\left\|\begin{array}{c}\text { HuGE } \\
\text { Nav. }\end{array}\right\|\left[\begin{array}{l}\text { Gene } \\
\text { Cards }\end{array}\right. \\
\text { NCBI gene summary } \\
\text { GAD associations \& P-value } \\
\text { Gene Prospector (HuGE) score } \\
\text { Gene Cards name synonyms }\end{array}$} \\
\hline \multicolumn{12}{|c|}{ Final Ranked Autism Output } \\
\hline $\begin{array}{l}\text { Gene } \\
\text { Symbol }\end{array}$ & $\begin{array}{c}\text { Genotator } \\
\text { Score }\end{array}$ & Ensembl ID & Gene Name & Synonyms & Chr. & Location & \# Refs. & \# DBs & $\begin{array}{l}\text { HuGE } \\
\text { Score }\end{array}$ & $\begin{array}{r}\text { GAD A } \\
Y\end{array}$ & $\begin{array}{l}\text { ssociations } \\
\text { es/No }\end{array}$ \\
\hline SLC6A4 & 136.7 & ENSG108576 & Solute Carrier... & $5-\mathrm{HTT}|5-\mathrm{HTTLPR}| \ldots$ & 17 & $17 q 11.1-q 12$ & 26 & 6 & 1.335 & & $2 / 4$ \\
\hline NRXN1 & 27.2 & ENSG179915 & Neurexin $1 \ldots$ & - & 2 & $2 \mathrm{p} 16.3$ & 5 & 8 & 0.262 & & $0 / 0$ \\
\hline FMR1 & 22.6 & ENSG102081 & Fragile $\mathrm{X} \ldots$ & FMRP|FRAXA|... & $\mathrm{x}$ & $\mathrm{Xq} 27.3$ & 6 & 3 & 0.204 & & $1 / 0$ \\
\hline PTEN & 19.6 & ENSG171862 & Phosphatase... & MHAM|PTEN1 $\mid \ldots$ & 10 & $10 \mathrm{q} 23.3$ & 4 & 7 & 0.188 & & $0 / 0$ \\
\hline \multicolumn{12}{|c|}{$\begin{array}{l}\text { Figure } 1 \text { Genotator algorithm. A user inputs a disease term into the search field of the Genotator web resource http://genotator.hms.harvard. } \\
\text { edu to initiate the pipeline. Genotator then simultaneously queries the databases listed in Table } 1 \text { to generate an unordered set of genes while } \\
\text { resolving synonyms and removing duplicate entries. The algorithm then gathers characteristics from specific databases, principally including } \\
\text { GAD, Gene Prospector (from HuGE Navigator), and NCBI, in order to build an attribute vector and to calculate a relevance score (scoring } \\
\text { algorithm detailed in the Implementation section, dark red fields are used in calculating the final Genotator score). The complete set of results, } \\
\text { including the Genotator score, associated gene attributes and supporting publications, are displayed directly in the website and made available } \\
\text { for download. }\end{array}$} \\
\hline
\end{tabular}

the GS score, thus enabling users the flexibility to retain the original scoring scheme or to define an alternative strategy. We devised the GS to serve as guide for gene prioritization that best captures the history of biomedical research findings while also ensuring adjustability of the threshold for inclusion/exclusion of genes.

\section{Evaluation}

We elected to use three trusted, manually updated, and disease-specific databases to provide (1) a list of vetted candidate genes that have clear association to the disease based on published research (linkage studies, genome-wide association studies, etc.), and (2) an independent ranking of the strength of association between the genes and the disease of interest against which to compare ranked results from Genotator. The three databases, SFARI Gene, PDGene, and AlzGene target Autism Spectrum Disorder (ASD), Parkinson Disease (PD), and Alzheimer's Disease (AD), respectively. SFARI gene is a leading repository of genetic information for ASD that is updated with high frequency by manual curators. PDGene is one of the most trusted web resources for genes associated with PD and has previously been used to validate the Gene Prospector scoring algorithm in $\mathrm{Yu}$ et al. [9]. AlzGene [6] has a similar structure to PDGene, and is also widely regarded as an authoritative source of information on the genes associated with AD. To generate a metric for ranking the genes reported by SFARI, we subtracted the total number of negative from the total number of positive associations that were directly reported in the database. PDGene and AlzGene provided a ranking of the top gene candidates in section of their websites called "TopGenes". At the time of writing, PDGene listed 32 and AlzGene listed 40 top genes. In addition, both resources assigned a label of "strong", "moderate", or "weak" to each top gene candidate based upon amount of evidence, extent of replication and protection from bias [10]. By utilizing these resources as a baseline for comparison, we could determine how well the automated procedures employed by Genotator compared to standards of manual annotation, both in terms of coverage of published research as well as in terms of prioritization of gene candidates.

\section{Website}

We designed a web resource for open access to the Genotator pipeline, available at http://genotator.hms.harvard. edu. The site has two primary components, one for initiating a query through a request form, and another for storing results under a disorder name (Figure 2). Results are stored persistently, together with the creation date. A user may request to update the results for a specific 
A.

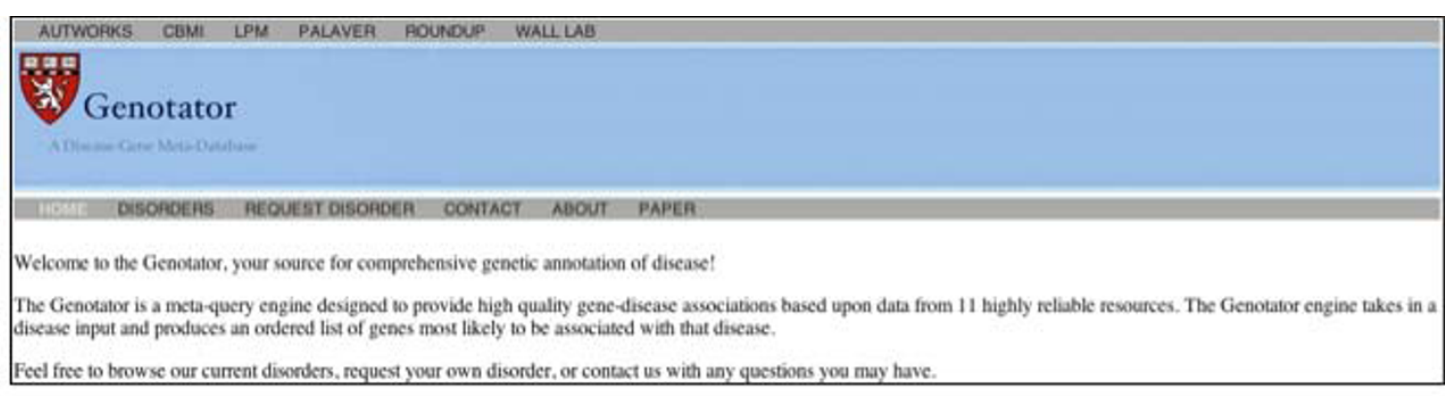

B.

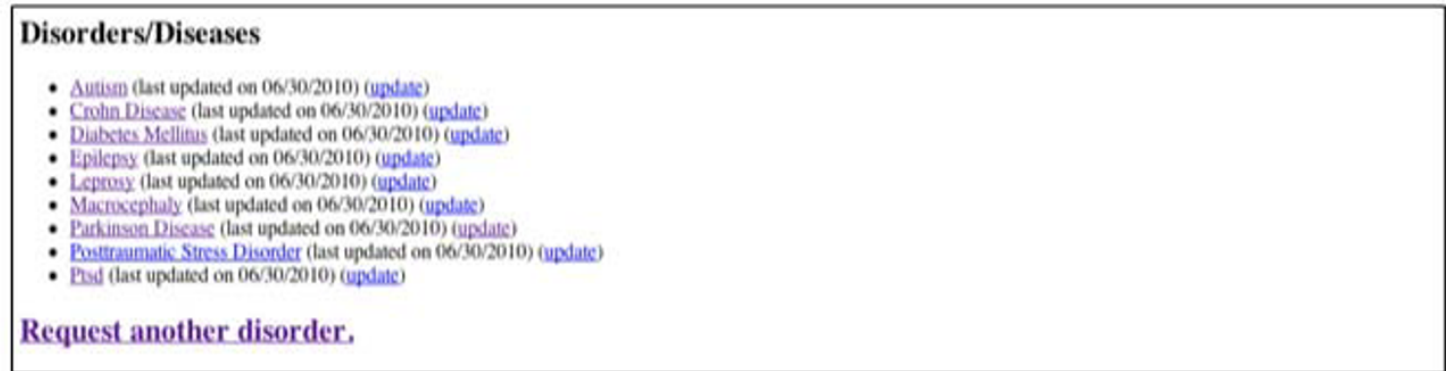

C.

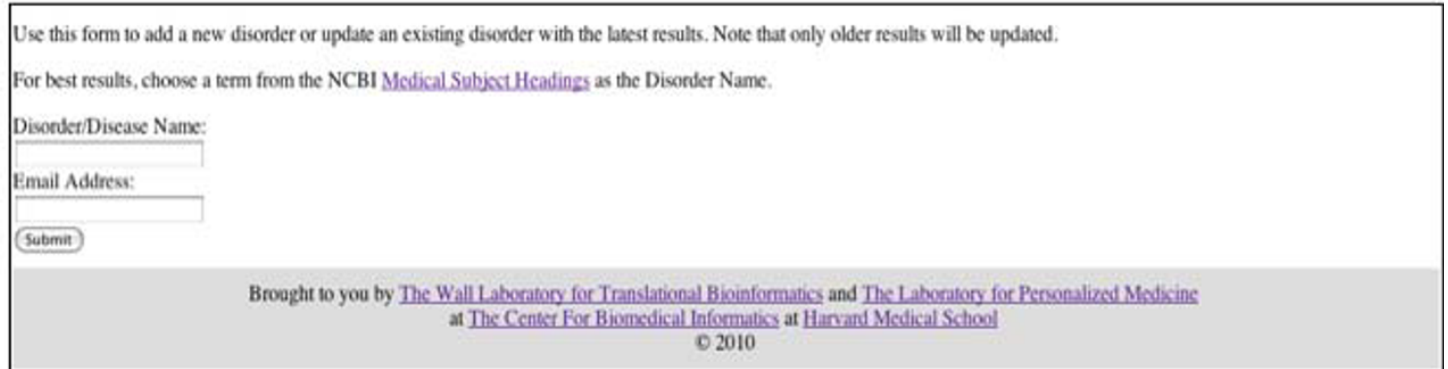

Figure 2 Screen shot of the main components of Genotator. Genotator is freely accessible at http://genotator.hms.harvard.edu. (A) The site consists of a splash page, (B) a disorders/diseases page that stores the complete set of results for all queries in alphabetical order, (C) and a query page that accepts a single disease or comma separated disease list and email address for alerting users when the query completes.

disorder if the results are likely to be outdated based on the last creation date. The request form requires a disorder name, following the standard vocabulary of the Unified Medical Language System, and an active email address. An automatic email is sent to the user when the pipeline completes. The results are then displayed in the "Disorders" tab and saved until updated. Each result set can be displayed in the browser or downloaded in full as a .txt file. The output contains a presence/absence matrix of the databases in which the gene appears; this gives the user the ability to select among the 11 databases and also to rank/reorder the results using criteria other than the Genotator score.

\section{Results}

Genotator yielded 663 genes for ASD, 1273 genes for PD, and 2682 genes for AD (full sets of results provided as Additional files 1, 2, and 3). Out of 4618 genes found from all three queries, $77 \%$ were reported in GeneCards and $43 \%$ in HuGE Navigator, well above the total numbers of genes added by other databases that each contributed less than $31 \%$ of the data (Table 3). Nevertheless, all but OMIM and GenAtlas provided at least some nonoverlapping gene information. In fact, a total of 2514 genes, $54 \%$ of the total found by Genotator, were listed as linked to the disease in only one database (Figure 3), suggesting that their inclusion within the Genotator workflow provided new, and potentially valuable information about the genes involved in human disease.

\section{Autism}

When using "Autism" as the query term in the Genotator disease search, 663 genes were returned. Six of the top 10 genes returned were listed among the most promising autism candidates in a recent review (Table 4) [11], demonstrating that the top ranked genes by Genotator match recent advances in our understanding of autism genetics. Using our method to rank the 197 SFARI genes, we compared the ordered lists from SFARI and Genotator. Genotator found a total of $77 \%$ 
Table 3 The percent contribution of disease candidate genes from each of the 11 databases totaled over autism, Parkinson's Disease, and Alzheimer Disease

\begin{tabular}{lr}
\hline Database & \% Contribution \\
\hline GeneCards & 76.85 \\
HuGE Navigator & 43.09 \\
WikiGenes & 30.51 \\
Genetic Association Database & 11.02 \\
UniProt & 4.87 \\
Your Favorite Gene & 3.23 \\
Human Gene Mutation Database & 3.20 \\
PharmGKB & 2.88 \\
Online Mendelian Inheritance in Man & 2.27 \\
Entrez Gene & 1.52 \\
GenAtlas & 1.23 \\
\hline
\end{tabular}

(152 out of the 197 SFARI 10 genes). All of the top 10 SFARI genes were included in the Genotator set, as well as 19 out of the top 20, 29 out of the top 30, 35 out of the top 40, and 41 out of the top 50.

\section{Parkinson's Disease}

As in Yu et al. 2008, we used the well-known PDGene database as a source for validation of the accuracy and coverage of Genotator. The PDGene database provided

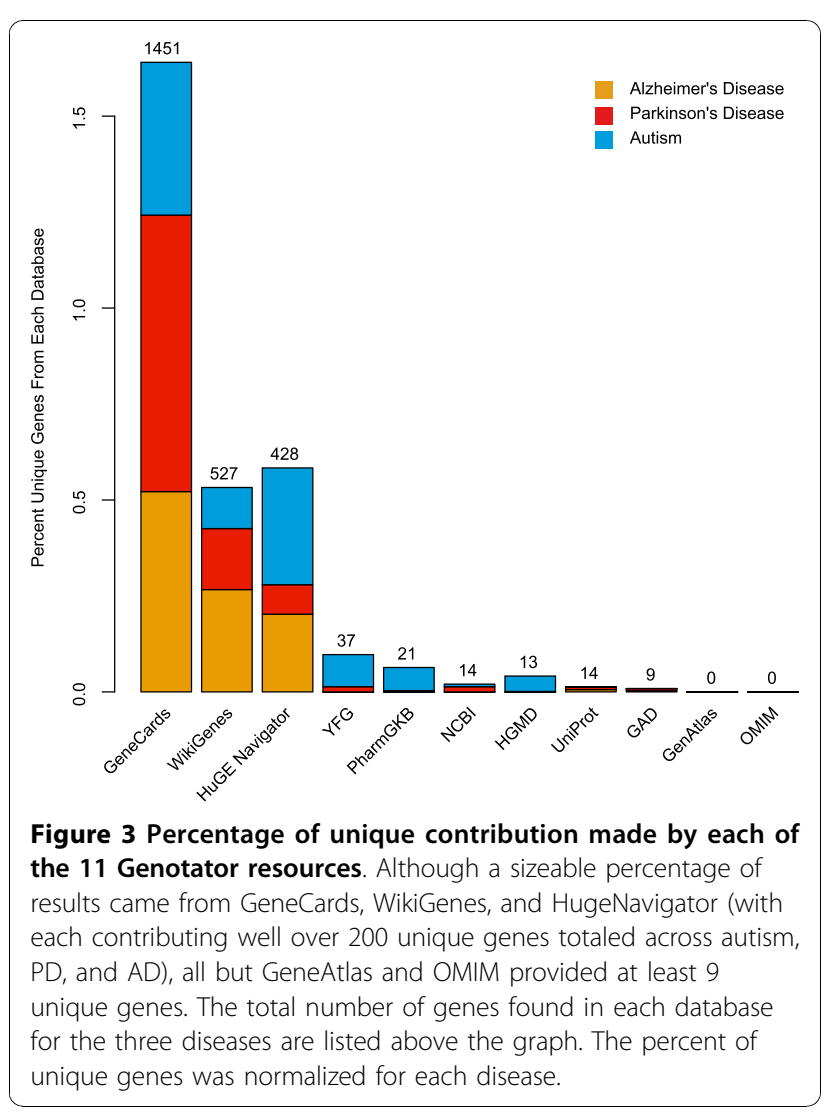

a relative ranking (based on HuGENet/Venice grades [10]) that enabled us to determine the extent of overlap with Genotator, both in terms of coverage and strength of association to the disease. Twenty-one of the 32 PDGene "Top Results" genes were in the top 10th percentile of the results returned by Genotator, and in total $58 \%$ (312/540 PDGene genes) were found to be in common (Table 5). In addition, 6 of the top 10 Genotator genes were listed among the most promising PD gene candidates in a recent review (Table 5) [12], indicating that Genotator appropriately prioritized leading research in the field.

\section{Alzheimer Disease}

As a final use case, we focused on AD and the wellknown AlzGene database. Similar to the PDGene database, AlzGene provided a relative ranking (based on HuGENet/Venice grades[10]) that enabled us to determine the extent of overlap with Genotator in terms of coverage and strength of association to the disease. Of the three disease use cases, Genotator appeared to perform best with Alzheimer Disease. Thirty-four of the 40 AlzGene "Top Results" genes were in the top 10th percentile of the results returned by Genotator, and in total $74 \%(486 / 660)$ of the candidate genes reported in AlzGene were found by Genotator (Table 6).

\section{Discussion}

As we advance into the era of personalized medicine, our ability to annotate the human genome with clinically actionable information is paramount. An important step in that annotation process is accurate characterization of the genetic etiology of any human disease. Numerous informatics approaches have been and are being developed to assist in this process, including methods for filtering biomedical knowledge for gene-disease association (e.g. [13], [14]), as well as full scale natural language processing approaches $[15,16]$, although the corpora necessary for both high precision and recall remain incomplete [16]. As these strategies have matured, an abundance of databases have emerged to provide summaries of recent and historical advances in human disease research. However, because these databases differ in their coverage of genes and annotation content, it is challenging for a researcher to develop a complete picture for a single disease or set of diseases of interest. In order to facilitate multi-database searching and to provide a more complete picture of advances in genetic research of human diseases, we developed a software tool called "Genotator". Genotator generates a comprehensive set of results for any disease by integrating gene and annotation data from 11 externally accessible and best-of-breed genetic resources. The results from Genotator are ranked using a scoring system that integrates bibliomic and genomic 
Table 4 Top scoring autism genes ranked on Genotator score

\begin{tabular}{|c|c|c|c|c|}
\hline Gene & Score & Literature Support & Reference & $\begin{array}{c}\text { AG } \\
\text { Classification }\end{array}$ \\
\hline SLC6A4 & 136.7 & $\begin{array}{l}\text { Linkage and association analysis at the serotonin transporter (SLC6A4) locus in a rigid-compulsive } \\
\text { subset of autism. }\end{array}$ & {$[32]$} & Probable \\
\hline NRXN1 & 27.2 & $\begin{array}{l}\text { Intragenic rearrangements in NRXN1 in three families with autism spectrum disorder, developmental } \\
\text { delay, and speech delay. }\end{array}$ & [33] & Promising \\
\hline FMR1 & 22.6 & Association and transmission analysis of the FMR1 IVS10 + 14C-T variant in autism & [34] & Probable \\
\hline PTEN & 19.6 & $\begin{array}{l}\text { Subset of individuals with autism spectrum disorders and extreme macrocephaly associated with } \\
\text { germline PTEN tumour suppressor gene mutations. }\end{array}$ & [35] & Probable \\
\hline FRAXA* & 17.9 & Point mutation analysis of the FMR-1 gene in autism. & [36] & \\
\hline FRAXE* & 17.9 & $\begin{array}{l}\text { Cognitive, behavioral, and neuroanatomical assessment of two unrelated male children expressing } \\
\text { FRAXE. }\end{array}$ & [37] & \\
\hline FRAXF* & 17.3 & Mental impairment and attention deficit hyperactivity disorder in a family with FRAXF. & [38] & \\
\hline CNTNAP2 & 15.9 & Linkage, association, and gene-expression analyses identify CNTNAP2 as an autism-susceptibility gene. & {$[39,35]$} & Probable \\
\hline UBE3A & 14.5 & Linkage disequilibrium at the Angelman syndrome gene UBE3A in autism families. & {$[40]$} & Probable \\
\hline $\mathrm{CDH} 10$ & 12 & Common genetic variants on 5p14.1 associate with autism spectrum disorders. & [41] & \\
\hline
\end{tabular}

The table lists the title and reference of the research study supporting the gene-disease association together with the official gene symbol. We used the review article by Abrahams and Geschwind (2008) as a source for the most promising autism gene candidates (AG classification). Starred genes are those that did not appear in SFARI Gene. The complete results are available online as Additional file 1.

data and provides a preliminary likelihood of strength of association for use in future thesis testing.

To test the content of Genotator and assess the efficacy of its scoring system, we applied Genotator to three separate diseases: Autism Spectrum Disorder (ASD), Parkinson's Disease (PD) and Alzheimer Disease (AD), and compared our results to the three web resources devoted to manual curation of these diseases, SFARI gene, PDgene, and AlzGene, respectively. Genotator's results were in high agreement, with over $75 \%$ in common with the gene lists provided by SFARI gene for autism, nearly $60 \%$ in common with the PDGene for PD and almost $75 \%$ in common with AlzGene for AD. Furthermore, the rank order provided by Genotator matched the prioritizations by these resources, especially among the most highly 12 ranked cohort of genes, supporting the notion that Genotator provides similar coverage and quality to that available from manually curated, well-funded resources that are under active development.

In addition, we were able to demonstrate the value-add provided through integration of the 11 different resources used by Genotator. Nearly every database reported genes not reported by any of the other databases, replete with sufficient justification for the gene-disease link (Figure 3). Thus, Genotator can achieve algorithmically what would otherwise require extensive manual labor. Genotator also provides an enriched output with features often lacking from other disease annotation including synonym disambiguation, standard HGNC nomenclature, and the ability to

Table 5 Top 10 Parkinson's Disease Genes ranked on Genotator score

\begin{tabular}{|c|c|c|c|c|}
\hline Gene & Score & Literature Support & Reference & $\begin{array}{l}\text { WRW } \\
\text { Mention }\end{array}$ \\
\hline LRRK2 & 105.1 & Frequency of LRRK2 mutations in early-and late-onset Parkinson disease. & [42] & Y \\
\hline MAPT & 60.8 & Different MAPT haplotypes are associated with Parkinson's disease and progressive supranuclear palsy. & [43] & Y \\
\hline SNCA & 59.8 & $\begin{array}{l}\text { Genome-wide association study confirms SNPs in SNCA and the MAPT region as common risk factors for } \\
\text { Parkinson disease. }\end{array}$ & [44] & Y \\
\hline PARK2 & 59.6 & Case-control study of the parkin gene in early-onset Parkinson disease. & [45] & Y \\
\hline APOE & 34.7 & Phenotypic associations of tau and ApoE in Parkinson's disease. & [46] & \\
\hline GBA & 21.4 & Genotype-phenotype correlations between GBA mutations and Parkinson disease risk and onset. & [47] & Y \\
\hline BDNF & 19.5 & $\begin{array}{l}\text { BDNF Val66Met polymorphism is associated with cognitive impairment in Italian patients with Parkinson's } \\
\text { disease. }\end{array}$ & [48] & \\
\hline DRD2 & 18.7 & Association of DRD3 and GRIN2B with impulse control and related behaviors in Parkinson's disease. & [49] & \\
\hline MAOB & 17.1 & Association of variations in monoamine oxidases A and B with Parkinson's disease subgroups. & [50] & \\
\hline PINK1 & 16.8 & $\begin{array}{l}\text { Parkin and PINK1 mutations in early-onset Parkinson's disease: comprehensive screening in publicly } \\
\text { available cases and control. }\end{array}$ & [51] & Y \\
\hline
\end{tabular}

The table lists the title and reference of the research study supporting the gene-disease association together with the official gene symbol. We used the recent review article by Wider, Ross, and Wszolek (2010) as a source for the most promising Parkinson's disease gene candidates (WRW Mention). A complete set of results is available online as Additional file 2. 


\begin{tabular}{|c|c|c|c|}
\hline Gene & Score & Literature Support & Reference \\
\hline APOE & 513 & Effect of APOE genotype on amyloid plaque load and gray matter volume in Alzheimer disease. & [52] \\
\hline PSEN1 & 45.4 & Early Onset Alzheimer's Disease with Spastic Paraparesis, Dysarthria and Seizures and N135 S Mutation in PSEN. & [53] \\
\hline ACE & 28.4 & $\begin{array}{l}\text { Amyloid-beta-Related Genes SORL1 and ACE are Genetically Associated With Risk for Late-onset Alzheimer Disease in } \\
\text { the Chinese Population. }\end{array}$ & [54] \\
\hline PRNP & 23.1 & Earlier onset of Alzheimer's disease: risk polymorphisms within PRNP, PRND, CYP46, and APOE genes. & [55] \\
\hline BCHE & 22.7 & $\begin{array}{l}\text { Dipeptidyl carboxypeptidase } 1 \text { (DCP1) and butyrylcholinesterase (BCHE) gene interactions with the apolipoprotein E } \\
\text { epsilon4 allele as risk factors in Alzheimer's disease and in Parkinson's disease with coexisting Alzheimer pathology. }\end{array}$ & [56] \\
\hline APOC1 & 20.8 & $\begin{array}{l}\text { APOE and APOC1 promoter polymorphisms and the risk of Alzheimer disease in African American and Caribbean } \\
\text { Hispanic individuals }\end{array}$ & [57] \\
\hline IL1B & 19.9 & Assessment of Alzheimer's disease case-control associations using family-based methods. & [58] \\
\hline IL1A & 19.5 & Pharmacogenomics in Alzheimer's disease. & [59] \\
\hline MTHFR & 19.3 & Association of MTHFR gene polymorphism C677T with susceptibility to late-onset Alzheimer's disease. & [60] \\
\hline BDNF & 17.5 & $\begin{array}{l}\text { Association between BDNF Val66Met polymorphism and Alzheimer disease, dementia with Lewy bodies, and Pick } \\
\text { disease. }\end{array}$ & [61] \\
\hline
\end{tabular}

The table lists the title and reference of the research study supporting the gene-disease association together with the official gene symbol. A complete set of results is available online as Additional file 3.

download the entire dataset including annotations, pubmed ids, and scores.

As the boundaries between diseases become more obscured, and as our definitions evolve in the wake of new genetic information, resources that provide high coverage of human disease are becoming increasingly more important. While Genotator will not obviate the need for manually curated disease-specific databases going forward, it will enable researchers to keep pace with the research being done on their disease of interest, including those for which devoted websites do not currently exist.

\section{Conclusions}

Genotator is a comprehensive biomedical informatics tool that integrates over a host of mainstream databases to provide automatic and up-to-date information on any human disease. Based on our analysis using three well-studied disorders, we confirmed that the results generated by Genotator match the quality and coverage of manually curated and disease-specific databases. This outcome, coupled with the highly flexible and detailed output, make Genotator a novel and valuable contribution to the field.

\section{Availability and Requirements}

Software Name: Genotator

Project home page: http://genotator.hms.harvard.edu

Programming Languages: Java, Python; source code available by request

\section{Additional material}

Additional file 1: Complete Genotator results for autism. Contains the complete set of genes identified by Genotator as linked to autism together with the full set of attributes gathered by the Genotator resource (Figure 1)
Additional file 2: Complete Genotator results for Parkinson's Disease. Contains the complete set of genes identified by Genotator as linked to Parkinson Disease together with the full set of attributes gathered by the Genotator resource (Figure 1).

Additional file 3: Complete Genotator results for Alzheimer Disease. Contains the complete set of genes identified by Genotator as linked to Alzheimer Disease together with the full set of attributes gathered by the Genotator resource (Figure 1).

\section{Acknowledgements}

We thank Gisela Gonzalez for work with Genotator validation, Jack Kosmicki for his improvements to the Genotator website, Isaac S. Kohane and Mark Boguski for useful discussions and ideas, and Russ Altman and Wei Yu for constructive critiques of an earlier version of the manuscript. This research was facilitated through funding from NIMH under grant number 1R01MH090611-01A1 awarded to DPW.

\section{Author details}

${ }^{1}$ Center for Biomedical informatics, Harvard Medical School, Boston, MA 02115. ${ }^{2}$ Department of Biomedical Informatics, Columbia University, New York, NY 10032.

\section{Authors' contributions}

DPW conceived the study, participated in algorithm design, analysis, and code development, and wrote the manuscript. RP designed and validated the algorithms, participated in code development, and wrote the manuscript. MT implemented the pipeline with assistance from DPW and JYJ. VF assisted in algorithm development and manuscript preparation. TFD developed the website and edited the manuscript. PJT conceived the study, assisted in algorithm design and analysis, and participated in the writing. All authors read and approved the final document.

\section{Competing interests}

The authors declare that they have no competing interests.

Received: 2 July 2010 Accepted: 29 October 2010

Published: 29 October 2010

\section{References}

1. Online Mendelian Inheritance in Man, OMIM (TM). McKusick-Nathans Institute of Genetic Medicine, Johns Hopkins University (Baltimore, MD) and National Center for Biotechnology Information, National Library of Medicine (Bethesda, MD), September 7, 2010. [http://www.ncbi.nlm.nih. gov/omim/]. 
2. Stenson PD, Mort M, Ball EV, Howells K, Phillips AD, Thomas NS, Cooper DN The Human Gene Mutation Database: 2008 update. Genome Med 2009, 1(1):13.

3. Rebhan M, Chalifa-Caspi V, Prilusky J, Lancet D: GeneCards: integrating information about genes, proteins and diseases. Trends Genet 1997, 13(4):163.

4. Banerjee-Basu S, Packer A: SFARI Gene: an evolving database for the autism research community. Dis Model Mech 2010, 3(3-4):133-135.

5. The PDGene Database. Alzheimer Research Forum. [http://www.pdgene. org/].

6. Bertram L, McQueen M, Mullin K, Blacker D, Tanzi R: Systematic metaanalyses of Alzheimer disease genetic association studies: the AlzGene database. Nat Genet 2007, 39(1):17-23.

7. Yu W, Gwinn M, Clyne M, Yesupriya A, Khoury MJ: A navigator for human genome epidemiology. Nat Genet 2008, 40(2):124-125.

8. Becker KG, Barnes KC, Bright TJ, Wang SA: The genetic association database. Nat Genet 2004, 36(5):431-432.

9. Yu W, Wulf A, Liu T, Khoury MJ, Gwinn M: Gene Prospector: An evidence gateway for evaluating potential susceptibility genes and interacting risk factors for human diseases. 2009, 1-8.

10. Ioannidis JPA, Boffetta P, Little J, O'Brien TR, Uitterlinden AG, Vineis P, Balding DJ, Chokkalingam A, Dolan SM, Flanders WD, et al: Assessment of cumulative evidence on genetic associations: interim guidelines. Int J Epidemiol 2008, 37(1):120-132.

11. Abrahams BS, Geschwind DH: Advances in autism genetics: on the threshold of a new neurobiology. Nat Rev Genet 2008, 9(5):341-355.

12. Wider C, Ross OA, Wszolek ZK: Genetics of Parkinson disease and essential tremor. Current Opinion in Neurology 2010.

13. Hoffmann $\mathrm{R}$, Valencia A: Implementing the iHOP concept for navigation of biomedical literature. Bioinformatics 2005, 21(Suppl 2):ii252-258.

14. Yue P, Melamud E, Moult J: SNPs3D: candidate gene and SNP selection for association studies. BMC Bioinformatics 2006, 7:166

15. Krallinger M, Leitner $F$, Valencia $A$ : Analysis of biological processes and diseases using text mining approaches. Methods Mol Biol 2010, 593:341-382.

16. Cano C, Monaghan T, Blanco A, Wall DP, Peshkin L: Collaborative textannotation resource for disease-centered relation extraction from biomedical text. J Biomed Inform 2009, 42(5):967-977.

17. [http://www.genecards.org/].

18. [http://geneticassociationdb.nih.gov/].

19. [http://hugenavigator.net/].

20. [http://www.hgmd.cf.ac.uk/ac/index.php].

21. [http://www.ncbi.n/m.nih.gov/omim/].

22. [http://www.sigmaaldrich.com/life-science/your-favorite-gene-search.html].

23. Consortium U: The Universal Protein Resource (UniProt) in 2010. Nucleic Acids Research 2010, , 38 Database: D142-148.

24. [http://www.uniprot.org/]

25. Klein TE, Chang JT, Cho MK, Easton KL, Fergerson R, Hewett M, Lin Z, Liu Y, Liu S, Oliver DE, et al: Integrating genotype and phenotype information: an overview of the PharmGKB project. Pharmacogenetics Research Network and Knowledge Base. Pharmacogenomics J 2001, 1(3):167-170

26. [http://www.pharmgkb.org/].

27. [http://www.ncbi.n/m.nih.gov/protein/?db=gene].

28. Hoffmann R: A wiki for the life sciences where authorship matters. Nat Genet 2008, 40(9):1047-1051.

29. [http://www.wikigenes.org/].

30. Frézal J: Genatlas database, genes and development defects. C R Acad Sci III, Sci Vie 1998, 321(10):805-817.

31. [http://genatlas.medecine.univ-paris5.fr/]

32. McCauley JL, Olson LM, Dowd M, Amin T, Steele A, Blakely RD, Folstein SE, Haines JL, Sutcliffe JS: Linkage and association analysis at the serotonin transporter (SLC6A4) locus in a rigid-compulsive subset of autism. Am J Med Genet B Neuropsychiatr Genet 2004, 127B(1):104-112.

33. Wiśniowiecka-Kowalnik B, Nesteruk M, Peters SU, Xia Z, Cooper ML, Savage $S$, Amato RS, Bader P, Browning MF, Haun $C L$, et al: Intragenic rearrangements in NRXN1 in three families with autism spectrum disorder, developmental delay, and speech delay. Am J Med Genet B Neuropsychiatr Genet 2010.

34. Vincent JB, Thevarkunnel S, Kolozsvari D, Paterson AD, Roberts W, Scherer SW: Association and transmission analysis of the FMR1 IVS10 +
14C-T variant in autism. Am J Med Genet B Neuropsychiatr Genet 2004, 125B(1):54-56.

35. Butler MG, Dasouki MJ, Zhou X-P, Talebizadeh Z, Brown M, Takahashi TN, Miles $J H$, Wang $\mathrm{CH}$, Stratton R, Pilarski $\mathrm{R}$, et al: Subset of individuals with autism spectrum disorders and extreme macrocephaly associated with germline PTEN tumour suppressor gene mutations. J Med Genet 2005, 42(4):318-321.

36. Vincent JB, Konecki DS, Munstermann E, Bolton P, Poustka A, Poustka F, Gurling HM: Point mutation analysis of the FMR-1 gene in autism. Mol Psychiatry 1996, 1(3):227-231.

37. Abrams MT, Doheny KF, Mazzocco MM, Knight SJ, Baumgardner TL, Freund LS, Davies KE, Reiss AL: Cognitive, behavioral, and neuroanatomical assessment of two unrelated male children expressing FRAXE. Am J Med Genet 1997, 74(1):73-81.

38. Ehlers S, Billstedt E, Wahlstrom J: Mental impairment and attention deficit hyperactivity disorder in a family with FRAXF. Neurocase 1999.

39. Alarcón M, Abrahams BS, Stone JL, Duvall JA, Perederiy JV, Bomar JM, Sebat J, Wigler M, Martin CL, Ledbetter $\mathrm{DH}$, et al: Linkage, association, and gene-expression analyses identify CNTNAP2 as an autism-susceptibility gene. Am J Hum Genet 2008, 82(1):150-159.

40. Nurmi EL, Bradford Y, Chen Y, Hall J, Arnone B, Gardiner MB, Hutcheson HB, Gilbert JR, Pericak-Vance MA, Copeland-Yates SA, et al: Linkage disequilibrium at the Angelman syndrome gene UBE3A in autism families. Genomics 2001, 77(1-2):105-113.

41. Wang K, Zhang H, Ma D, Bucan M, Glessner JT, Abrahams BS, Salyakina D, Imielinski M, Bradfield JP, Sleiman PMA, et al: Common genetic variants on 5p14.1 associate with autism spectrum disorders. Nature 2009, 459(7246):528-533.

42. Clark LN, Wang Y, Karlins E, Saito L, Mejia-Santana H, Harris J, Louis ED, Cote LJ, Andrews H, Fahn S, et al: Frequency of LRRK2 mutations in earlyand late-onset Parkinson disease. Neurology 2006, 67(10):1786-1791.

43. Ezquerra M, Pastor P, Gaig C, Vidal-Taboada JM, Cruchaga C, Muñoz E, Martí M-J, Valldeoriola F, Aguilar M, Calopa M, et al: Different MAPT haplotypes are associated with Parkinson's disease and progressive supranuclear palsy. Neurobiology of aging 2009.

44. Edwards TL, Scott WK, Almonte C, Burt A, Powell EH, Beecham GW, Wang L, Züchner S, Konidari I, Wang G, et al: Genome-wide association study confirms SNPs in SNCA and the MAPT region as common risk factors for Parkinson disease. Ann Hum Genet 2010, 74(2):97-109.

45. Clark LN, Afridi S, Karlins E, Wang Y, Mejia-Santana H, Harris J, Louis ED, Cote $L$, Andrews $H$, Fahn S, et al: Case-control study of the parkin gene in early-onset Parkinson disease. Arch Neurol 2006, 63(4):548-552.

46. Papapetropoulos S, Farrer MJ, Stone JT, Milkovic NM, Ross OA, Calvo L, McQuorquodale D, Mash DC: Phenotypic associations of tau and ApoE in Parkinson's disease. Neurosci Lett 2007, 414(2):141-144.

47. Gan-Or Z, Giladi N, Rozovski U, Shifrin C, Rosner S, Gurevich T, Bar-Shira A, Orr-Urtreger A: Genotype-phenotype correlations between GBA mutations and Parkinson disease risk and onset. Neurology 2008, 70(24):2277-2283.

48. Guerini FR, Beghi E, Riboldazzi G, Zangaglia R, Pianezzola C, Bono G, Casali C, Di Lorenzo C, Agliardi C, Nappi G, et al: BDNF Val66Met polymorphism is associated with cognitive impairment in Italian patients with Parkinson's disease. Eur J Neurol 2009, 16(11):1240-1245.

49. Lee J-Y, Lee EK, Park SS, Lim J-Y, Kim HJ, Kim JS, Jeon BS: Association of DRD3 and GRIN2B with impulse control and related behaviors in Parkinson's disease. Mov Disord 2009, 24(12):1803-1810.

50. Parsian A, Racette B, Zhang ZH, Rundle M, Perlmutter JS: Association of variations in monoamine oxidases $A$ and $B$ with Parkinson's disease subgroups. Genomics 2004, 83(3):454-460.

51. Brooks J, Ding J, Simon-Sanchez J, Paisan-Ruiz C, Singleton AB, Scholz SW: Parkin and PINK1 mutations in early-onset Parkinson's disease: comprehensive screening in publicly available cases and control. J Med Genet 2009, 46(6):375-381.

52. Drzezga A, Grimmer T, Henriksen G, Mühlau M, Perneczky R, Miederer I, Praus C, Sorg C, Wohlschläger A, Riemenschneider M, et al: Effect of APOE genotype on amyloid plaque load and gray matter volume in Alzheimer disease. Neurology 2009, 72(17):1487-1494.

53. Rudzinski L, Fletcher R, Dickson D: Early Onset Alzheimer's Disease with Spastic Paraparesis, Dysarthria and Seizures and N135 S Mutation in PSEN1. Alzheimer disease. 2008. 
54. Ning M, Yang Y, Zhang Z, Chen Z, Zhao T, Zhang D, Zhou D, Xu J, Liu Z, Wang Y, et al: Amyloid-beta-Related Genes SORL1 and ACE are Genetically Associated With Risk for Late-onset Alzheimer Disease in the Chinese Population. Alzheimer disease and associated disorders 2010.

55. Golanska E, Hulas-Bigoszewska K, Sieruta M, Zawlik I, Witusik M, Gresner SM, Sobow T, Styczynska M, Peplonska B, Barcikowska M, et al: Earlier onset of Alzheimer's disease: risk polymorphisms within PRNP, PRND, CYP46, and APOE genes. J Alzheimers Dis 2009, 17(2):359-368.

56. Mattila KM, Rinne JO, Röyttä M, Laippala P, Pietilä T, Kalimo H, Koivula T, Frey H, Lehtimäki T: Dipeptidyl carboxypeptidase 1 (DCP1) and butyrylcholinesterase (BCHE) gene interactions with the apolipoprotein $E$ epsilon4 allele as risk factors in Alzheimer's disease and in Parkinson's disease with coexisting Alzheimer pathology. J Med Genet 2000, 37(10):766-770.

57. Tycko B, Lee JH, Ciappa A, Saxena A, Li C-M, Feng L, Arriaga A, Stern Y, Lantigua R, Shachter N, et al: APOE and APOC1 promoter polymorphisms and the risk of Alzheimer disease in African American and Caribbean Hispanic individuals. Arch Neurol 2004, 61(9):1434-1439.

58. Schjeide B-MM, McQueen MB, Mullin K, DiVito J, Hogan MF, Parkinson M, Hooli B, Lange C, Blacker D, Tanzi RE, et al: Assessment of Alzheimer's disease case-control associations using family-based methods. Neurogenetics 2009, 10(1):19-25.

59. Cacabelos R: Pharmacogenomics in Alzheimer's disease. Methods in molecular biology (Clifton, NJ) 2008, 448:213-357.

60. Wang B, Jin F, Kan R, Ji S, Zhang C, Lu Z, Zheng C, Yang Z, Wang L: Association of MTHFR gene polymorphism C677T with susceptibility to late-onset Alzheimer's disease. J Mol Neurosci 2005, 27(1):23-27.

61. Fehér $A$, Juhász A, Rimanóczy A, Kálmán J, Janka Z: Association between BDNF Val66Met polymorphism and Alzheimer disease, dementia with Lewy bodies, and Pick disease. Alzheimer disease and associated disorders 2009, 23(3):224-228.

\section{Pre-publication history}

The pre-publication history for this paper can be accessed here: http://www.biomedcentral.com/1755-8794/3/50/prepub

\section{doi:10.1186/1755-8794-3-50}

Cite this article as: Wall et al: Genotator: A disease-agnostic tool for genetic annotation of disease. BMC Medical Genomics 2010 3:50.

\section{Submit your next manuscript to BioMed Central and take full advantage of:}

- Convenient online submission

- Thorough peer review

- No space constraints or color figure charges

- Immediate publication on acceptance

- Inclusion in PubMed, CAS, Scopus and Google Scholar

- Research which is freely available for redistribution

Submit your manuscript at www.biomedcentral.com/submit
C Biomed Central 